This is an open access article distributed under the CC BY Attribution 4.0 International license.

\title{
Contribution of Extrahepatic Aldehyde Oxidase Activity to Human Clearance ${ }^{\mathrm{S}}$
}

\author{
Kirk D. Kozminski, Jangir Selimkhanov, Scott Heyward, and Michael A. Zientek \\ Takeda Pharmaceuticals Limited, San Diego, California (K.D.K., J.S., M.A.Z.); and Bio/VT, Baltimore, Maryland (S.H.)
}

Received November 14, 2020; accepted June 10, 2021

\begin{abstract}
Aldehyde oxidase (AOX) is a soluble, cytosolic enzyme that metabolizes various $\mathbf{N}$-heterocyclic compounds and organic aldehydes. It has wide tissue distribution with highest levels found in liver, kidney, and lung. Human clearance projections of AOX substrates by in vitro assessments in isolated liver fractions (cytosol, S9) and even hepatocytes have been largely underpredictive of clinical outcomes. Various hypotheses have been suggested as to why this is the case. One explanation is that extrahepatic AOX expression contributes measurably to AOX clearance and is at least partially responsible for the often observed underpredictions. Although AOX expression has been confirmed in several extrahepatic tissues, activities therein and potential contribution to overall human clearance have not been thoroughly studied. In this work, the AOX enzyme activity using the $S 9$ fractions of select extrahepatic human tissues (kidney, lung, vasculature, and intestine) were measured using carbazeran as a probe substrate. Measured activities were scaled to a whole-body clearance using best-available parameters
\end{abstract}

and compared with liver S9 fractions. Here, the combined scaled AOX clearance obtained from the kidney, lung, vasculature, and intestine is very low and amounted to $<1 \%$ of liver. This work suggests that AOX metabolism from extrahepatic sources plays little role in the underprediction of activity in human. One of the notable outcomes of this work has been the first direct demonstration of AOX activity in human vasculature.

\section{SIGNIFICANCE STATEMENT}

This work demonstrates aldehyde oxidase (AOX) activity is measurable in a variety of extrahepatic human tissues, including vasculature, yet activities and potential contributions to human clearance are relatively low and insignificant when compared with the liver. Additionally, the modeling of the tissue-specific in vitro kinetic data suggests that AOX may be influenced by the tissue it resides in and thus show different affinity, activity, and modified activity over time.

\section{Introduction}

Aldehyde oxidase is a molybdenum cofactor-containing cytosolic enzyme recognized for its potential to oxidize various nitrogen-containing heterocyclic compounds and organic aldehydes (Beedham, 2001; Kitamura et al., 2006; Garattini et al., 2008; Pryde et al., 2010; Terao et al., 2016; Rashidi and Soltani, 2017). Catalytically, the mechanism involves nucleophilic attack at an electron-deficient carbon and insertion of oxygen from water. Apart from oxidation reactions, research shows that aldehyde oxidase (AOX) could also act as a reductase toward $N$ oxides, sulfoxides, and heterocycles under hypoxic conditions (Kitamura and Tatsumi, 1984a,b). It has also been demonstrated more recently that AOX can catalyze the hydrolysis of amide bonds (Sodhi et al., 2015).

Interest in AOX has increased considerably in recent years, and drug metabolism and pharmacokinetics laboratories have implemented assays to screen for its activity. This interest primarily stems from changing chemical-derivation or synthesis trends that, although they improve drug properties, may result in clearance by non-P450 pathways. Thus, although introduction of groups, such as azaheterocycles, may improve

This work received no external funding.

The authors report no conflicts of interest.

https://dx.doi.org/10.1124/dmd.120.000313.

S This article has supplemental material available at dmd.aspetjournals.org. $\log$ P, solubility, and overall P450 liabilities, it may also increase potential for AOX-mediated metabolism. Carbazeran (Kaye et al., 1984), zoniporide (Dalvie et al., 2010), SGX523 (Diamond et al., 2010), and Lu AF09535 (Jensen et al., 2017) are examples of drug candidates that failed clinically as a result of unexpected poor pharmacokinetics or toxic metabolite formation due in part to aldehyde oxidase.

AOX-mediated metabolism can be readily captured in vitro through the use of human cytosolic and S9 liver fractions. When AOX activity is suspected, confidence can be increased through coincubation of test substrates with an AOX-specific inhibitor, such as hydralazine (Strelevitz et al., 2012). Though AOX-mediated metabolism can be correctly identified preclinically, the clearance in human has generally been underpredicted by in vitro assays and sometimes quite substantially. A number of estimates suggest the in vitro-to-in vivo correlation underprediction of in vivo intrinsic clearance could be as much as 10-fold on average for AOX substrates when plasma protein binding is taken into account (Zientek et al., 2010; Akabane et al., 2012; Hutzler et al., 2013; De Sousa Mendes et al., 2020). Various explanations have been offered in the literature as to why this may be the case, and these include possible loss of enzyme activity during tissue collection and preservation and a loss of enzyme activity over the time course of an in vitro assay. Regarding the latter, it has recently been proposed that regeneration of the AOX enzyme in vitro may be rate-limited by flow of electrons from the molybdenum pterin cofactor to the flavin adenine dinucleotide for the reduction of oxygen (Abbasi et al., 2019). In that work, the

ABBREVIATIONS: $A O X$, aldehyde oxidase; $\mathrm{CL}_{\mathrm{AOX}}$, total $\mathrm{AOX}$ clearance; $\mathrm{CL}_{\text {int }}$, intrinsic clearance; $\mathrm{CL}_{\text {int,scaled }}$, scaled $\mathrm{CL}_{\text {int }} ; \mathrm{f}_{\mathrm{u}}$, fraction unbound; HPLC, high-performance liquid chromatography; $\mathrm{K}_{\mathrm{M}}$, Michaelis-Menten constant; LC/MS/MS, liquid chromatography-tandem mass spectrometry; P450, cytochrome P450. 
authors proposed a modulated activity model to capture the early fast rate of the enzyme to improve clearance predictions. However, even with this model, some residual underprediction persists. Another possibility often speculated in the literature is that contributions to AOX metabolism from extrahepatic tissue could be a key factor in the underpredictions. Immunohistochemical studies have shown that AOX is broadly distributed throughout the human body (Moriwaki et al., 2001). The kidneys, adrenal glands, lungs, and reproductive tissue are rich sources among other tissues. A more recent study has confirmed the presence and activity of AOX in human skin (Manevski et al., 2014). Although there is no current evidence suggesting that AOX metabolism at any one organ or tissue bed could rival that occurring at the liver, it cannot be ruled out that the collective contributions of many compartments could be significant.

Our objective in this current work was to measure the rates of AOX activity in the $S 9$ fractions from various extrahepatic tissues known or suspected to express the AOX enzyme and to use best-available physiologic parameters to estimate potential contributions to total human AOX clearance. Studies were conducted using carbazeran as a probe substrate, a classic example of a compound with human clearance that is significantly underpredicted by liver tissue fractions. In this work, carbazeran is an ideal tool because of its high intrinsic activity, and although it has been observed to undergo glucuronidation in hepatocytes (Sharma et al., 2012), it is metabolized exclusively by AOX to a single product, 4-oxo-carbazeran in human cytosol or S9 without cofactors (Kaye et al., 1985; Xie et al., 2019) (Fig. 1).

Although we cannot capture AOX activity in every extrahepatic tissue compartment, the exercise does reveal the potential significance of extrahepatic contribution to the overall human AOX clearance of a drug and the collective role AOX containing extrahepatic tissue may play in the often-observed underprediction phenomenon.

\section{Materials and Methods}

\section{Materials}

The human vasculature S9 fractions obtained as a gift from BioIVT (Baltimore, MD) were prepared from the interior linings of iliac arteries collected during standard liver harvesting. The yield of vascular S9 per weight of tissue was calculated from the total protein yielded from the preparation as measured by the BCA protein assay (Thermo Fisher Scientific, Rockford, IL) divided by the weight of tissue used in the preparation, and this is represented as the average of three donors (one male and two females). The human kidney (whole kidney, mixed sex, pool of 8), lung (nonsmoker, mixed sex, pool of 4), and intestinal (duodenal and jejunal, prepared by elution, mixed sex, pool of 15) S9 fractions were procured from XenoTech (Kansas City, KS). Human liver S9 fractions were procured from BioIVT (mixed sex, pool of 150). Carbazeran and 4-oxocarbazeran were procured from Toronto Research Chemicals (Ontario, Canada), and hydralazine was procured from Sigma Aldrich (St. Louis, MO). Dialysis membranes (6-8 $\mathrm{kDa}$ molecular mass cut-off) for protein binding were procured from HTDialysis (Gales Ferry, CT). Water and acetonitrile were of HPLC grade
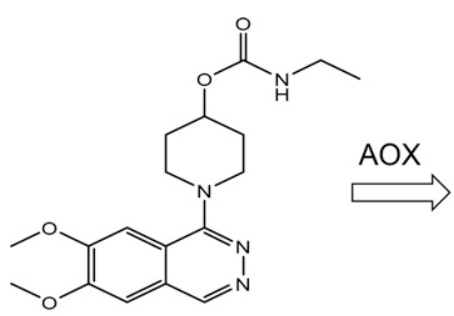

carbazeran

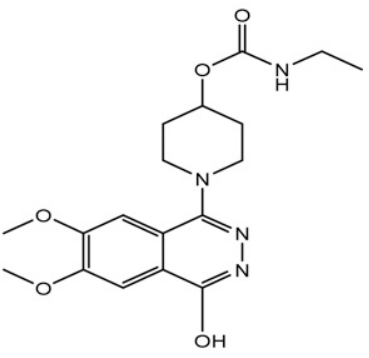

4-oxo-carbazeran
Fig. 1. Metabolism of carbazeran to 4-oxo-carbazeran by AOX. and were procured from Fisher Scientific (Fair Lawn, NJ). All other reagents used in the study were of extrapure grade.

\section{Methods}

Tissue S9 Incubations. Each tissue-specific extrahepatic S9 fraction (kidney, lung, vasculature, intestinal) was incubated at a final protein concentration of 1 $\mathrm{mg} / \mathrm{ml}$ in phosphate buffer (100 mM, pH 7.4) with $1,3,10$, and $30 \mu \mathrm{M}$ carbazeran. Liver S9 fraction was incubated at a final protein concentration of $0.1 \mathrm{mg} /$ $\mathrm{ml}$ in an identical manner. The lower end of the carbazeran concentration range $(1 \mu \mathrm{M})$ was chosen specifically to represent concentrations lower than the Michaelis-Menten constant $\left(\mathrm{K}_{\mathrm{M}}\right)$ values reported in the literature $(3-6 \mu \mathrm{M})$ and assumed to provide the highest rate of metabolite formation (Chen et al., 2019; Tan et al., 2020; Uehara et al., 2020). Thus, the lower end of the concentrations range is assumed to provide an accurate account of maximum intrinsic clearance $\left(\mathrm{CL}_{\text {int }}\right)\left(\sim \mathrm{V}_{\max } / \mathrm{K}_{\mathrm{M}}\right)$. Pooled S9 products were incubated in duplicate (lung, kidney, intestinal) or triplicate (liver) at each substrate concentration. For vasculature S9, each individual donor was tested separately at each test concentration. No cofactors were added to any incubations. Incubations (300 $\mu \mathrm{l}$ starting volume) were conducted in 96 deep well plates (Thomson Instruments, Oceanside, CA) using a Thermomixer (Eppendorf, Hamburg, Germany) at $37^{\circ} \mathrm{C}$ with a shaking speed of $600 \mathrm{rpm}$. Aliquots $(30 \mu \mathrm{l})$ were removed at $0,3,7,15,30,60$, and 90 minutes postincubation and quenched with $200 \mu \mathrm{l}$ of chilled acetonitrile containing a proprietary internal standard. Parallel incubations were conducted in the presence of hydralazine (100 $\mu \mathrm{M}$ final concentration), a known AOX inhibitor. All collected samples were centrifuged at $4000 \times \mathrm{g}$ for 10 minutes, and supernatants were diluted 3-fold in water prior to liquid chromatography-tandem mass spectrometry (LC/MS/MS) injection. Authentic standards of 4-oxo-carbazeran were prepared in the nonfortified $\mathrm{S} 9$ tissue matrices and processed in an identical manner.

Protein Binding. The protein binding assay for extrahepatic S9 fractions was conducted using equilibrium dialysis. Tissue-specific S9 fractions $(1 \mathrm{mg} / \mathrm{ml}$ protein) fortified with $1 \mu \mathrm{M}$ compound and blank $100 \mathrm{mM}$ phosphate buffer, $\mathrm{pH}$ 7.4, were placed on opposite sides of a divided 96-well dialysis membrane device. Samples (triplicates) were dialyzed against buffer for a total of 6 hours at $37^{\circ} \mathrm{C}$ and $5 \% \mathrm{CO}_{2}$ on an oscillating platform inside a standard cell culture incubator. At the end of the incubation period, donor and receiver samples were matrix-matched (10 $\mu \mathrm{l}$ of S9 study sample and $40 \mu \mathrm{l}$ of blank assay buffer or 40 $\mu \mathrm{l}$ of buffer study sample and $10 \mu \mathrm{l}$ of nonfortified S9 matrix) and were quenched with $200 \mu \mathrm{l}$ of chilled acetonitrile containing a proprietary internal standard. Quenched samples were centrifuged at $4000 \times \mathrm{g}$ for 10 minutes, and supernatants were diluted 3-fold in water prior to LC/MS/MS injection.

LC/MS/MS Analysis. Analysis was conducted with an API4500 triple quadrupole mass spectrometer (AB Sciex, Ontario, Canada). Samples were analyzed with electrospray ionization in the positive mode with a source temperature of $500^{\circ} \mathrm{C}$. The parent $>$ daughter transition monitored for carbazeran was $361.2>$ 218.1 atomic mass unit, and the collision energy was set at $38 \mathrm{~V}$. The parent $>$ daughter transition monitored for 4-oxo-carbazeran was $377.1>288.1$ atomic mass unit, and the collision energy was set at $23 \mathrm{~V}$. The HPLC column (Kinetex $\mathrm{C} 18-\mathrm{XB}, 50 \times 2.1 \mathrm{~mm}, 5-\mu \mathrm{m}$ particles) was procured from Phenomenex (Torrance, $\mathrm{CA}$ ). The mobile phase consisted of HPLC-grade water with $0.1 \%$ formic acid and acetonitrile with $0.1 \%$ formic acid for components $\mathrm{A}$ and $\mathrm{B}$, respectively. The mobile phase was held at $5 \% \mathrm{~B}$ and ramped to $95 \% \mathrm{~B}$ over 1.3 minutes at a flow rate of $0.6 \mathrm{ml} / \mathrm{min}$. The total run time was 1.5 minutes. $\mathrm{LC} /$ MS/MS chromatograms were collected and integrated with Analyst software (version 1.6). A standard curve (1-500 nM) was used to quantify 4-oxo-carbazeran formation in all extrahepatic S9 study samples (kidney, lung, vasculature, intestinal). For liver S9 study samples, the standard curve range was shifted up to 8-fold higher (8-4000 nM) depending on substrate incubation concentration to capture the higher amounts of metabolite formed in these incubations. Assay performance was accepted based on linearity throughout the dynamic range of the curve ( $\mathrm{R}>0.99$ with $1 / \mathrm{x}^{2}$ weighting) and back calculation of standards to within $20 \%$ of the nominal value.

Data Analysis. Consistent with supporting data acquired during the studies presented within this manuscript, the AOX pathway was presumed to be the only pathway contributing to carbazeran clearance utilizing $S 9$ tissue fractions, with 4-oxo-carbazeran being the sole metabolite formed. As such, carbazeran $\mathrm{CL}_{\text {int }}$ in each tissue was estimated based on 4-oxo-carbazeran time-course data obtained in the various S9 incubations and calculated according to 


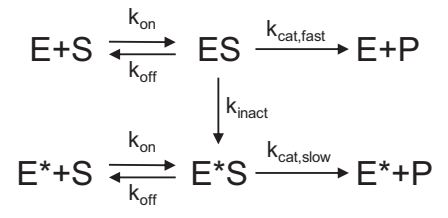

Fig. 2. The AOX-modulated activity model describes product $\mathrm{P}$ formation from substrate $\mathrm{S}$ by enzyme $\mathrm{E}$ through the formation of the enzyme-substrate complex (ES), which also leads to the formation ( $\mathrm{k}_{\text {inact }}$ ) of a less catalytically active version of the enzyme $\mathrm{E}^{*}\left(\mathrm{k}_{\text {cat,slow }}<\mathrm{k}_{\text {cat.fast }}\right)$. The substrate and enzyme binding $\left(\mathrm{k}_{\text {on }}\right)$ and dissociation $\left(\mathrm{k}_{\text {off }}\right)$ rate constants are unaffected by the change in the enzyme's catalytic activity.

$$
C L_{\text {int }}=\frac{V_{\text {max }, \text { tissue }}}{K_{M, \text { tissue }}}
$$

In eq. $1, \mathrm{AOX}$ maximum 4-oxo-carbazeran formation rate $\left(V_{\text {max }}\right.$,tissue $=$ $\left.E_{\text {tissue }} \times k_{\text {cat }, \text { fast }}\right)$ and Michaelis-Menten constant $\left(K_{M, \text { tissue }}=\frac{k_{o n}+k_{\text {cat }} \text { fast }}{k_{\text {of }} \text {, tisue }}\right)$ were calculated using parameters of AOX-modulated activity model (Abbasi et al., 2019), which were estimated by fitting the model (Fig. 2) to the 4-oxo-carbazeran time-course data. In the model, $k_{\text {cat fast }}$ is the initial fast AOX catalytic rate constant, $E_{\text {tissue }}$ is the initial active AOX concentration in each of the tissues, $k_{\text {on }}$ is the binding rate constant, and $k_{\text {off, tissue }}$ is the tissue-specific unbinding rate constant. The model was implemented in MATLAB R2019 (MathWorks, Natick, MA) and simultaneously fit to 4-oxo-carbazeran mean concentration time-course data from all tissue S9 incubations using default fitnlm algorithm settings with a proportional error model and all model parameters assumed to be log-normally distributed. Description of the full model characterization can be found in the Supplemental Material.

The $\mathrm{CL}_{\text {int }}$ values were scaled to in vivo $\left(\mathrm{CL}_{\text {int,scaled }}\right)$ for each tissue according to

$$
C L_{\text {int }, \text { scaled }}=C L_{\text {int }} * \frac{m g S 9 \text { protein }}{g \text { tissue }} * \frac{g \text { tissue }}{\mathrm{kg} \text { body } w t}
$$

Total AOX clearance $\left(\mathrm{CL}_{\mathrm{AOX}}\right)$ contributions from liver, kidney, lung, and intestinal compartments were estimated by the well stirred model as follows:

$$
C L_{A O X}=\frac{Q_{b} *\left(f_{u, \text { plasma }} / R_{B P}\right) *\left(C L_{\text {int }, \text { scaled }} / f_{u, s 9}\right)}{Q_{b}+\left(f_{u, p l a s m a} / R_{B P}\right) *\left(C L_{\text {int }, \text { scaled }} / f_{u, s 9}\right)}
$$

in which $\mathrm{Q}_{\mathrm{b}}$ is blood flow to the tissue compartment, $\mathrm{f}_{\mathrm{u} \text {,plasma }}$ is unbound free fraction in plasma, $\mathrm{R}_{\mathrm{BP}}$ is the blood-to-plasma concentration distribution, and $\mathrm{f}_{\mathrm{u}, \mathrm{S} 9}$ is the free fraction in the $\mathrm{S} 9$ incubations. For vasculature, it was considered that there is continuous exposure to the blood throughout the body, and the blood flow restriction was removed. Furthermore, it was assumed that the iliac arterial tissue was representative of the entirety of the human vasculature. $\mathrm{CL}_{\mathrm{AOX}}$ from the vasculature was estimated as follows:

$$
C L_{A O X}=\left(f_{u, p l a s m a} / R_{B P}\right) *\left(C L_{\text {int, scaled }} / f_{f_{u, s 9}}\right)
$$

All physiologic parameter values used in the above equations are recorded in Table 1 . The $\mathrm{f}_{\mathrm{u}, \text { plasma }}$ and $\mathrm{R}_{\mathrm{BP}}$ values for carbazeran, 0.08 and 0.7 , respectively, were taken from a previous publication (Zientek et al., 2010). Carbazeran $\mathrm{f}_{\mathrm{u}, \mathrm{S} 9}$ was measured by equilibrium dialysis and determined to be $0.72,0.82,0.72$, and 0.74 for kidney, lung, vasculature, and intestinal $\mathrm{S} 9$ fractions $(1 \mathrm{mg} / \mathrm{ml})$, respectively. For the liver $\mathrm{S} 9$ fraction $(0.1 \mathrm{mg} / \mathrm{ml})$, carbazeran consumption by AOX is too extensive to measure binding by equilibrium dialysis. Here, liver $\mathrm{f}_{\mathrm{u}, \mathrm{S} 9}$ was calculated as 0.97 per the nonspecific binding model (Austin et al., 2002) as follows:

$$
f_{u, \text { liver } S 9}=\frac{1}{\left(\frac{[P]_{\text {extra-hepatics9 }}}{P]_{\text {livers9 }}} *\left(\frac{1-f_{u, \text { extra-hepatics }}}{f_{u, \text { extra-hepatics9 }}}\right)+1\right)}
$$

in which $[\mathrm{P}]_{\text {extra-hepatics9 }}$ is $1 \mathrm{mg} / \mathrm{ml},[\mathrm{P}]_{\text {liverS9 }}$ is $0.1 \mathrm{mg} / \mathrm{ml}$, and $f_{u, e x t r a-h e p a t i c s 9}$ is 0.75 , which is the average $f_{u}$ measured across all extrahepatic tissues (kidney, lung, vasculature, intestinal) studied.

\section{Results}

After the in vitro incubations with carbazeran, nonlinear formation of 4-oxo-carbazeran metabolite was observed and quantified against authentic standards in the liver, kidney, lung, and vasculature S9 fractions at all incubation concentrations (Fig. 3, A-E, respectively). Across all incubations, initial faster rate of 4-oxo-carbazeran formation was quickly followed by a slower rate of formation. Only negligible amounts of metabolite were detected in the intestinal S9 fractions and specifically only observed at the higher incubation concentrations (Fig. $3 \mathrm{~F}$ ) and associated with the slower rate of formation. Although the extent of carbazeran elimination was too low to be accurately measured in extrahepatic S9 fractions, it was easily observed in liver S9 fractions, and there was an approximate mass balance between substrate consumption and metabolite formation. A representative plot of carbazeran consumption versus 4-oxo-carbazeran formation for $1 \mu \mathrm{M}$ incubations in liver S9 fraction is shown in Fig. 3A. Coincubation of carbazeran with $100 \mu \mathrm{M}$ hydralazine, a selective mechanism-based inhibitor of AOX, significantly blocked metabolite formation in all incubations. In liver S9, there was a $93 \%$ decrease in metabolite formation at the highest test concentration $(30 \mu \mathrm{M})$ of carbazeran. Similarly, all extrahepatic tissues showed at least $81 \%$ decrease in metabolite formation at the same conditions. Relative concentrations of 4-oxo-carbazeran quantified at the end of the incubation period (90 minutes) for all carbazeran test concentrations, with and without presence of hydralazine, are presented in Fig. 4 for each tissue S9 fraction tested. Taken together, observed data in human S9 fractions without cofactors suggest that carbazeran is metabolized to a single product, 4-oxo-carbazeran, and this is mediated by the AOX pathway.

Despite minimal consumption of carbazeran by the various extrahepatic tissue S9 samples, 4-oxo-carbazeran metabolite formation quickly followed nonlinear kinetics that can be described by the AOX-modulated activity model (Abbasi et al., 2019). This model was able to accurately capture (adjusted $\mathrm{R}^{2}=0.99$ ) 4-oxo-carbazeran formation time-course data in all tissue S9 incubations (Fig. 3), with estimated parameter values

TABLE 1

Physiologic parameters used for scaling $\mathrm{CL}_{\text {int }}$ and estimating $\mathrm{CL}_{\mathrm{AOX}}$ contributions

\begin{tabular}{lcccl}
\hline Tissue & mg S9 Protein/g Tissue & g Tissue/kg b.wt. & Blood Flow Rate & \\
\hline & & $m l / m i n / k g$ & References \\
Liver & 120 & 21.4 & 20.7 & (Zientek et al., 2010; Cubitt et al., 2011) \\
kidney & $39^{a}$ & $4.6^{a}$ & 16.4 & (Obach et al., 2006; Scotcher et al., 2017) \\
Lung & $28^{a}$ & $10.4^{a}$ & 77.9 & (Myers et al., 2011; Levitzky, 2013; Scotcher et al., 2017) \\
Vasculature & $8.5^{b}$ & 14.3 & n/a & (Aird, 2005; Myers et al., 2011) \\
Intestine & $27^{a}$ & $1.1^{\text {a,c }}$ & 3.54 & (Obach et al., 2006) \\
\hline
\end{tabular}

n/a, not applicable

${ }^{a}$ Personal communication from XenoTech, LLC

${ }^{b}$ Personal communication from BioIVT

${ }^{c}$ Based on total wet weight of eluted enterocytes 
A

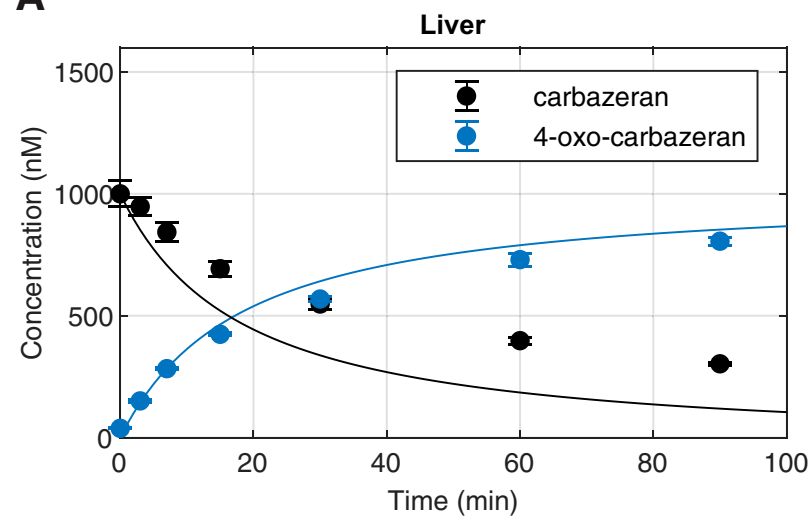

C

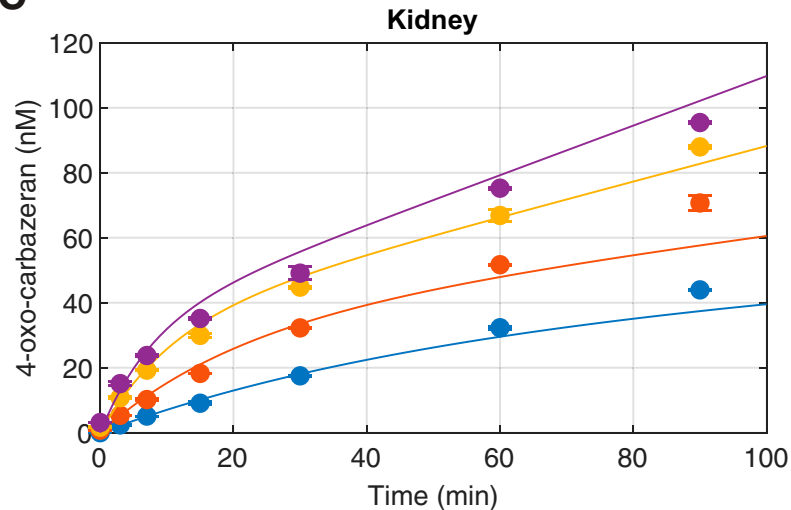

E

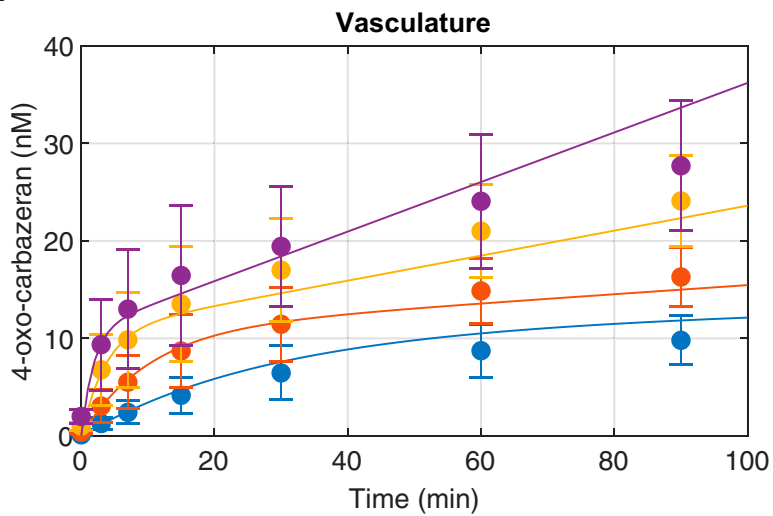

B

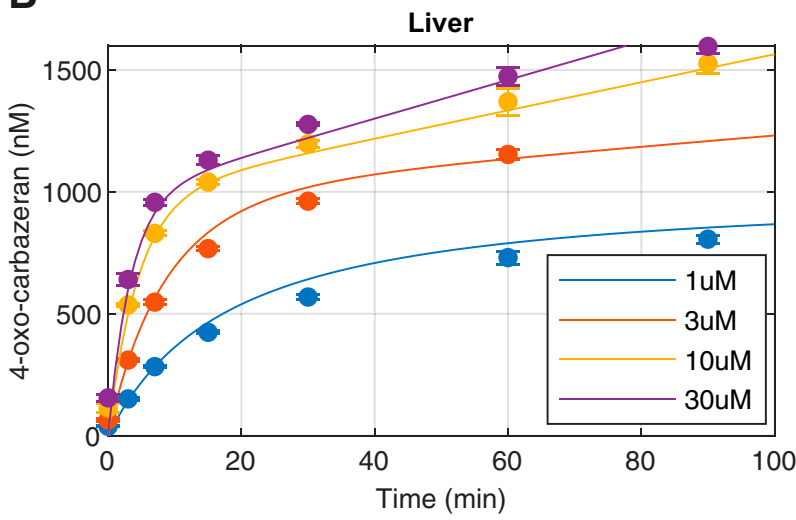

D

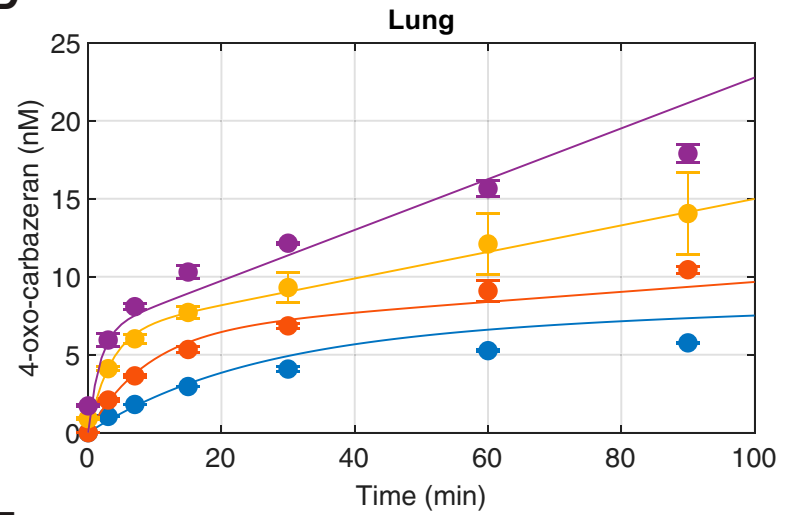

$\mathbf{F}$

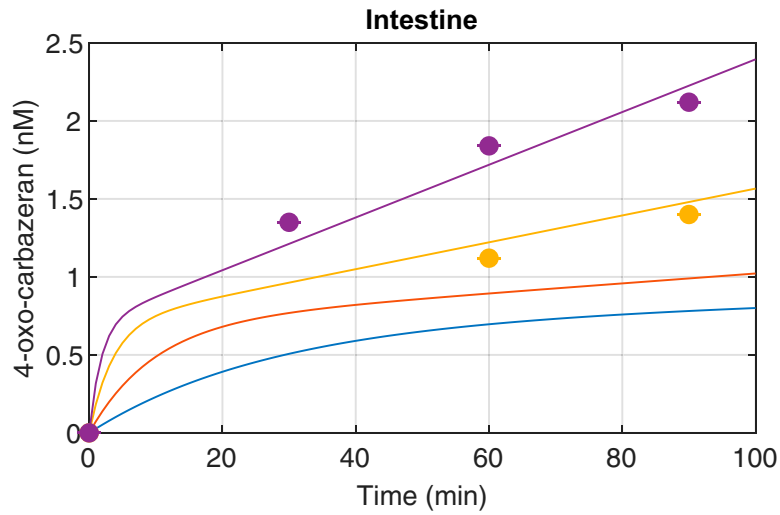

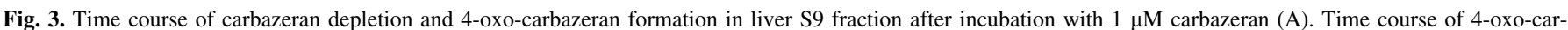

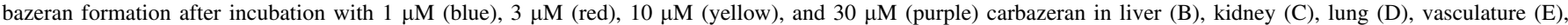

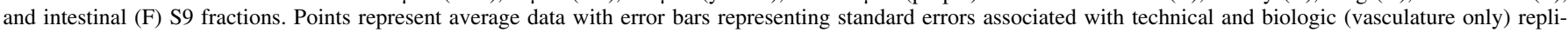
cates. The curves show AOX modulated activity model simulations based on simultaneous fit to 4-oxo-carbazeran time-course data from all tissue S9 fractions.

captured in Table 2. In the final model, liver and kidney were found to have a lower Michaelis-Menten constant value $(5.2 \mu \mathrm{M})$ relative to the other tissues $(21 \mu \mathrm{M})$ as well as different enzyme inactivation and slow catalytic rate constant values (Table 3). To estimate intestinal $\mathrm{S} 9 \mathrm{CL}_{\mathrm{int}}$ $(0.038 \mu \mathrm{l} / \mathrm{min} / \mathrm{mg} \mathrm{S} 9)$ despite minimal 4-oxo-carbazeran formation, it was necessary to assume that the intestinal AOX enzyme rate constants were the same as in other tissue's S9 fractions (lung and vasculature). Similarly, to estimate active AOX enzyme level in each tissue $\left(E_{\text {tissue }}\right)$, it was assumed that the AOX fast catalytic rate constant was the same across all tissues. Thus, we determined that the liver has the highest estimated AOX enzyme concentration level at $21 \mathrm{pmol} / \mathrm{mg} \mathrm{S} 9$ protein (Table 2). AOX intrinsic clearance estimates calculated according to eq. 1 were $670,1.2,0.35,0.58$, and $0.038 \mu \mathrm{l} / \mathrm{min} / \mathrm{mg}$, respectively, for liver, kidney, lung, vasculature, and intestine $\mathrm{S} 9$ fractions incubated with carbazeran (Table 3). The $\mathrm{CL}_{\text {int,scaled }}$ and $\mathrm{CL}_{\mathrm{AOX}}$, the values estimated in various extra-hepatic tissues, were very low relative to the liver (Table 3 ). Collectively, $\mathrm{CL}_{\mathrm{AOX}}$ estimates in the extrahepatic tissues sampled in this current work represent $<1 \%$ compared with that of the liver.

\section{Discussion}

Although the human liver is the richest source of AOX, the current study has demonstrated that AOX activity is clearly present and measurable in a variety of extrahepatic human tissues. Significantly, we demonstrate for the first time that AOX activity is measurable in the human vasculature, as represented by $\mathrm{S} 9$ fractions prepared from iliac arteries. 
A

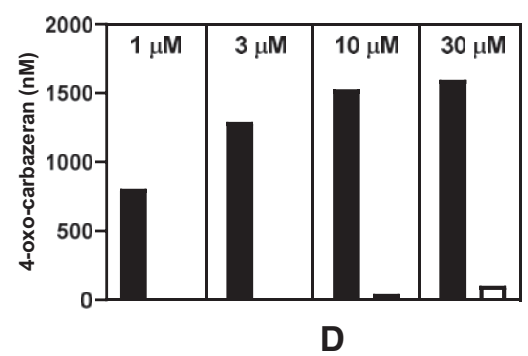

B

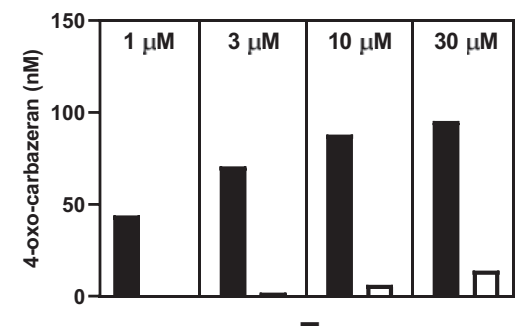

C

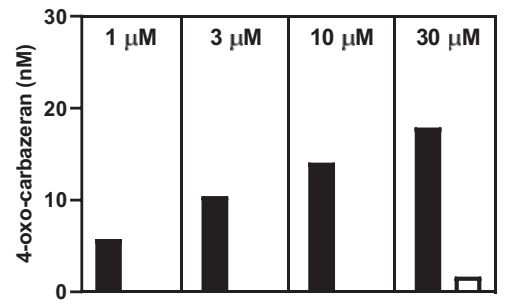

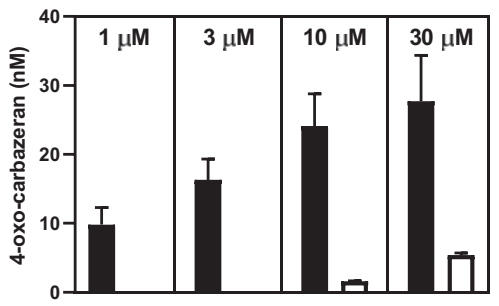

E

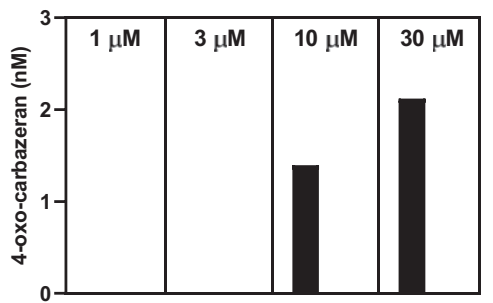

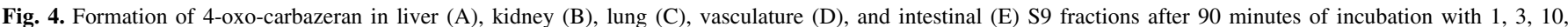
and $30 \mu \mathrm{M}$ carbazeran in absence $(\square)$ and presence $(\square)$ of $100 \mu \mathrm{M}$ hydralazine.

Given that AOX has been found to be expressed in a variety of extrahepatic human tissues beyond the scope of this current work (adrenal glands, reproductive tissue, adipose), it can be fully expected that measurable extrahepatic AOX activity can be found throughout the human body, which would further contribute to the metabolism of AOX substrates.

Given this backdrop, it seems plausible that the collective contributions to AOX metabolism by extrahepatic sources could at a minimum partially explain the underprediction of human clearance scaled from in vitro assays conducted with pooled hepatic S9 or cytosolic fractions. Admittedly, various assumptions were made in the current study when estimating a potential $\mathrm{CL}_{\mathrm{AOX}}$ contribution from a particular tissue compartment, and physiologic parameters may not be as accurate as those commonly used for liver tissue scaling. Regardless, these assumptions likely have little impact on the overall findings presented in this study, in which the extrahepatic tissues only provide a minor contribution to overall systemic clearance. Here, the collective estimated $\mathrm{CL}_{\mathrm{AOX}}$ of kidney, lung, vasculature, and intestinal compartments together contribute $<1 \%$ of that predicted by the liver.

The tissue fractions tested were chosen because of the identified expression levels of AOX in the tissue (Basit et al., 2020), the volume of tissue of the organ (Davies and Morris, 1993), and the lack of blood flow restriction pertaining to the tissue. Although it would have been desirable to study additional human tissues beyond the scope of this work, it is unlikely based on these criteria that any would contribute significantly to whole-body AOX clearance. For example, the adrenal glands are often cited as having rich AOX expression (Moriwaki et al., 2001; Gomez-Sanchez, 2007). However, adrenal glands are very small, and the combined weight of adult human adrenal glands is only roughly $10 \mathrm{~g}$ (Kreiner, 1982). Although adrenal glands may have a rich blood supply on a per-gram basis, total blood flow has been estimated at roughly $0.14 \%$ of cardiac output (Gomez-Sanchez, 2007) or what would amount to approximately $0.1 \mathrm{ml} / \mathrm{min} / \mathrm{kg}$. Similarly, contribution of human skin, which was demonstrated to have limited AOX activity (Manevski et al., 2014), to whole-body AOX clearance would also be insignificant when compared with liver.

Carbazeran, a phosphodiesterase inhibitor-1 inhibitor that produces concentration-dependent positive inotropic responses and is known for its greater than or equal to hepatic blood flow systemic clearance $(\geq 21$ $\mathrm{ml} / \mathrm{min} / \mathrm{kg}$ ) and being extensively metabolized to the 4-oxo-metabolite in vivo, was chosen as an ideal probe substrate to identify AOX activity in tissue S9 fractions. Carbazeran is also known for its specificity for AOX versus other enzymes in S9 fractions, especially since enzymes that require cofactors in vitro (i.e., uridine 5'-diphospho-glucuronosyltransferases and P450s) are of little consequence without addition of cofactors, which were excluded from the protocol. Additionally and perhaps most importantly to these experiments, carbazeran exhibits a rapid turnover rate providing its sensitivity as a marker even with very low AOX expression levels in tissue. Because of this fact, the number of potential substrates available to assess extrahepatic AOX activity was limited. In addition to carbazeran, zoniporide was tested during the course of these experiments using all of the aforementioned tissues.

TABLE 2

Modulated activity model parameter estimates

Values in brackets represent $95 \%$ confidence intervals.

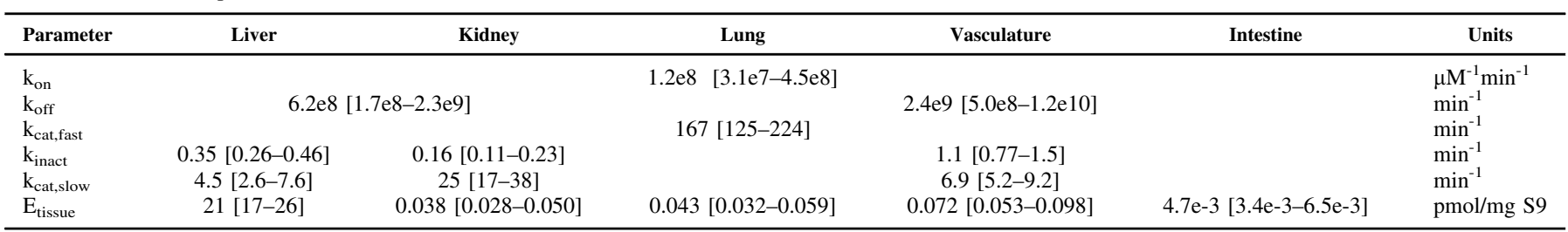


TABLE 3

Calculated parameters and scaled AOX clearance contributions

\begin{tabular}{|c|c|c|c|c|c|}
\hline Tissue & $\mathbf{K}_{\mathbf{M}}$ & $\mathbf{V}_{\max }$ & $\mathrm{CL}_{\text {int }}$ & $\mathrm{CL}_{\text {int } \text {,scaled }}$ & Total $\mathbf{C L}_{\mathrm{AOX}}$ \\
\hline & $\mu M$ & $\mathrm{pmol} / \mathrm{min} / \mathrm{mg} S 9$ & $\mu l / \min / m g S 9$ & $\mathrm{ml} / \mathrm{min} / \mathrm{kg}$ & $\mathrm{ml} / \mathrm{min} / \mathrm{kg}$ \\
\hline Liver & 5.2 & 3507 & 670 & 1721 & 19 \\
\hline Kidney & 5.2 & 6.3 & 1.2 & 0.22 & 0.034 \\
\hline Lung & 21 & 7.2 & 0.35 & 0.10 & 0.014 \\
\hline Vasculature & 21 & 12 & 0.58 & 0.071 & 0.011 \\
\hline Intestine & 21 & 0.78 & 0.038 & 0.0011 & 0.00017 \\
\hline
\end{tabular}

With protein concentrations up to $1 \mathrm{mg} / \mathrm{ml}$, zoniporide did not result in adequate substrate turnover even at enzyme-saturating substrate concentrations $(30 \mu \mathrm{M})$ and failed to provide measurable metabolite formation rates, thus disqualifying it as an applicable substrate (Supplemental Fig. 3).

The analysis of the data and scaling of organ-specific AOX clearance used the well stirred model. This particular model, as opposed to the dispersion model or parallel-tube model, was used because it presents the highest possible in vivo clearance estimate for each tissue's contribution to the overall systemic clearance in humans. For vasculature, the blood-flow restriction was removed entirely. Therefore, the possibility of an underprediction based on the scaling method has been minimized. An interesting observation of this work is that in all extrahepatic tissues studied the initial rate of 4-oxo-carbazeran production was followed by a rapid deceleration in product formation despite minimal consumption of carbazeran. It has been hypothesized by Abbasi and coworkers (2019) that AOX is likely slow to reduce oxygen in vitro, resulting in enzyme reduction that leads to the decelerated substrate turnover. We employed an AOX modulated activity model (Abbasi et al., 2019) to accurately capture the early rapid rate of AOX activity characterized by the fast catalytic rate constant. Since the early rapid rate of AOX activity in vitro is believed to most accurately represent in vivo AOX activity, the application of the AOX-modulated activity model provided us with a more accurate estimate of intrinsic clearance. Despite the more accurate estimate of the initial faster rate of substrate turnover, extrahepatic AOX contribution estimates were found to be very low.

By assuming that the AOX fast catalytic rate constant is the same across all tissues, the difference in AOX activity between various tissues, as determined by the early rapid rate of 4-oxo-carbazeran formation, can be attributed to the abundance of active AOX enzyme in S9 fractions. Thus, using the AOX modulated activity model, estimates of active AOX enzyme abundance in each tissue's S9 fraction were obtained. It was found that the active AOX abundance in the liver (21 $\mathrm{pmol} / \mathrm{mg} \mathrm{S} 9$ protein) is in general agreement with measured liver AOX abundance $(11.96 \pm 4.46 \mathrm{pmol} / \mathrm{mg} \mathrm{S} 9$ protein) described by Basit and colleagues (2020). In addition, the published extrahepatic AOX abundance levels for the heart and intestine were below the limit of quantification, which agrees with much lower estimated active AOX levels that we obtained using AOX activity (Table 2). In contrast, Basit et al. (2020) showed only an 8-fold difference in AOX abundance between kidney $(1.53 \pm 0.79 \mathrm{pmol} / \mathrm{mg} \mathrm{S} 9$ protein $)$ and liver, whereas our analysis of AOX activity data showed greater than 500-fold reduction in active kidney AOX abundance $(0.038 \mathrm{pmol} / \mathrm{mg} \mathrm{S} 9$ protein) relative to liver. Since enzyme abundance does not always correlate with activity, it is possible that our assumption of tissue-independent enzyme fast catalytic rate is incorrect, which could explain the observed disconnect. Tissue sample preparation differences among suppliers and laboratories, and perhaps between tissues, could also impact the resulting AOX activity and thus the model-derived active AOX enzyme tissue abundance estimates.
In support of potential differences in enzyme activity between tissues, it was necessary to introduce tissue-specific differences in several of the model's enzyme rate constants to accurately describe the full 4-oxo-carbazeran time-course data in kidney and liver S9 fractions (Supplemental Material). This observation suggests that it is possible that AOX enzyme activity could be different in various tissues and thus complicates the total metabolic clearance extrapolation based on a recombinant protein enzyme activity and tissue enzyme abundance levels as proposed by Basit et al. (2020). It is possible that sample differences between liver, kidney, and other tissues could have affected observed 4-oxo-carbazeran formation, which would impact interpretation of model-derived active AOX enzyme tissue abundance estimates.

This work suggests that future efforts may be best directed toward understanding aspects of tissue isolation and fraction preparation that may negatively impact AOX activity. Sanoh and coworkers (2012), who isolated human hepatocytes from humanized PhoenixBio mice and then used them to predict human in vivo intrinsic clearance, showed a 3-fold or greater underprediction from the line of unity. This direct comparison of in vivo clearance in humanized mice and the scaled hepatic clearance from hepatocytes isolated from the same animal suggests that the loss in AOX activity during preparation of liver cells and fractions may impact our ability to predict human in vivo AOX clearance. Furthermore, despite accounting for the lack of the active AOX enzyme regeneration during the experiment through the modulated activity model, unaccounted factors may affect the level of active AOX enzyme prior to the incubation. Perhaps additional systematic work pertaining to the complexity of enzyme activation may shed more light on the limited enzymatic activity of tissue isolates and ways to correct for it.

In conclusion, this work advances the narrative that AOX is active and measurable in a variety of extrahepatic human tissues, including the vasculature. However, the collective contribution of the tissues tested in these experiments to whole-body clearance of AOX substrates is very low compared with the liver, and they are unlikely to contribute significantly toward the often-observed underprediction of human AOX clearance.

\section{Authorship Contributions}

Participated in research design: Kozminski, Zientek. Conducted experiments: Kozminski.

Performed data analysis: Kozminski, Selimkhanov.

Wrote or contributed to the writing of the manuscript: Kozminski, Selimkhanov, Heyward, Zientek.

\section{References}

Abbasi A, Paragas EM, Joswig-Jones CA, Rodgers JT, and Jones JP (2019) Time course of aldehyde oxidase and why it is nonlinear. Drug Metab Dispos 47:473-483.

Aird WC (2005) Spatial and temporal dynamics of the endothelium. J Thromb Haemost 3:1392-1406.

Akabane T, Gerst N, Masters JN, and Tamura K (2012) A quantitative approach to hepatic clearance prediction of metabolism by aldehyde oxidase using custom pooled hepatocytes. Xenobiotica 42:863-871. 
Austin RP, Barton P, Cockroft SL, Wenlock MC, and Riley RJ (2002) The influence of nonspecific microsomal binding on apparent intrinsic clearance, and its prediction from physicochemical properties. Drug Metab Dispos 30:1497-1503.

Basit A, Neradugomma NK, Wolford C, Fan PW, Murray B, Takahashi RH, Khojasteh SC, Smith BJ, Heyward S, Totah RA, et al. (2020) Characterization of differential tissue abundance of major non-CYP enzymes in human. Mol Pharm 17:4114-4124.

Beedham C (2001) Molybdenum Hydroxylases, in Enzyme Systems that Metabolise Drugs and other Xenobiotics (Ioannides C, ed) p 576, Wiley-VCH.

Chen S, Austin-Muttitt K, Zhang LH, Mullins JGL, and Lau AJ (2019) In vitro and in silico analyses of the inhibition of human aldehyde oxidase by bazedoxifene, lasofoxifene, and structural analogues. J Pharmacol Exp Ther 371:75-86.

Cubitt HE, Houston JB, and Galetin A (2011) Prediction of human drug clearance by multiple metabolic pathways: integration of hepatic and intestinal microsomal and cytosolic data. Drug Metab Dispos 39:864-873.

Dalvie D, Zhang C, Chen W, Smolarek T, Obach RS, and Loi CM (2010) Cross-species comparison of the metabolism and excretion of zoniporide: contribution of aldehyde oxidase to interspecies differences. Drug Metab Dispos 38:641-654.

Davies B and Morris T (1993) Physiological parameters in laboratory animals and humans. Pharm Res 10:1093-1095.

De Sousa Mendes M, L Orton A, Humphries HE, Jones B, Gardner I, Neuhoff S, and Pilla Reddy V (2020) A laboratory-specific scaling factor to predict the in vivo human clearance of aldehyde oxidase substrates. Drug Metab Dispos 48:1231-1238.

Diamond S, Boer J, Maduskuie Jr TP, Falahatpisheh N, Li Y, and Yeleswaram S (2010) Speciesspecific metabolism of SGX523 by aldehyde oxidase and the toxicological implications. Drug Metab Dispos 38:1277-1285.

Garattini E, Fratelli M, and Terao M (2008) Mammalian aldehyde oxidases: genetics, evolution and biochemistry. Cell Mol Life Sci 65:1019-1048.

Gomez-Sanchez CE (2007) Regulation of adrenal arterial tone by adrenocorticotropin: the plot thickens. Endocrinology 148:3566-3568.

Hutzler JM, Obach RS, Dalvie D, and Zientek MA (2013) Strategies for a comprehensive under standing of metabolism by aldehyde oxidase. Expert Opin Drug Metab Toxicol 9:153-168.

Jensen KG, Jacobsen AM, Bundgaard C, Nilausen DO, Thale Z, Chandrasena G, and Jørgensen M (2017) Lack of exposure in a first-in-man study due to aldehyde oxidase metabolism: investigated by use of 14C-microdose, humanized mice, monkey pharmacokinetics, and in vitro methods. Drug Metab Dispos 45:68-75.

Kaye B, Offerman JL, Reid JL, Elliott HL, and Hillis WS (1984) A species difference in the presystemic metabolism of carbazeran in dog and man. Xenobiotica 14:935-945.

Kaye B, Rance DJ, and Waring L (1985) Oxidative metabolism of carbazeran in vitro by liver cytosol of baboon and man. Xenobiotica 15:237-242.

Kitamura S, Sugihara K, and Ohta S (2006) Drug-metabolizing ability of molybdenum hydroxylases. Drug Metab Pharmacokinet 21:83-98.

Kitamura S and Tatsumi K (1984a) Involvement of liver aldehyde oxidase in the reduction of nicotinamide N-oxide. Biochem Biophys Res Commun 120:602-606.

Kitamura S and Tatsumi K (1984b) Reduction of tertiary amine N-oxides by liver preparations: function of aldehyde oxidase as a major N-oxide reductase. Biochem Biophys Res Commun 121:749-754.

Kreiner E (1982) Weight and shape of the human adrenal medulla in various age groups. Virchows Arch A Pathol Anat Histol 397:7-15.

Levitzky M (2013) Pulmonary Physiology, McGraw-Hill Companies, New York, NY.

Manevski N, Balavenkatraman KK, Bertschi B, Swart P, Walles M, Camenisch G, Schiller H, Kretz O, Ling B, Wettstein R, et al. (2014) Aldehyde oxidase activity in fresh human skin. Drug Metab Dispos 42:2049-2057.
Moriwaki Y, Yamamoto T, Takahashi S, Tsutsumi Z, and Hada T (2001) Widespread cellular distribution of aldehyde oxidase in human tissues found by immunohistochemistry staining. Histol Histopathol 16:745-753

Myers JN, Gujja P, Neelagaru S, Hsu L, and Burkhoff D (2011) Noninvasive measurement of cardiac performance in recovery from exercise in heart failure patients. Clinics (São Paulo) 66:649-656.

Obach RS, Walsky RL, Venkatakrishnan K, Gaman EA, Houston JB, and Tremaine LM (2006) The utility of in vitro cytochrome P450 inhibition data in the prediction of drug-drug interactions. J Pharmacol Exp Ther 316:336-348.

Pryde DC, Dalvie D, Hu Q, Jones P, Obach RS, and Tran TD (2010) Aldehyde oxidase: an enzyme of emerging importance in drug discovery. J Med Chem 53:8441-8460.

Rashidi MR and Soltani S (2017) An overview of aldehyde oxidase: an enzyme of emerging importance in novel drug discovery. Expert Opin Drug Discov 12:305-316.

Sanoh S, Horiguchi A, Sugihara K, Kotake Y, Tayama Y, Ohshita H, Tateno C, Horie T, Kitamura S, and Ohta S (2012) Prediction of in vivo hepatic clearance and half-life of drug candidates in human using chimeric mice with humanized liver. Drug Metab Dispos 40:322-328

Scotcher D, Billington S, Brown J, Jones CR, Brown CDA, Rostami-Hodjegan A, and Galetin A (2017) Microsomal and cytosolic scaling factors in dog and human kidney cortex and application for in vitro-in vivo extrapolation of renal metabolic clearance. Drug Metab Dispos 45:556-568.

Sharma R, Strelevitz TJ, Gao H, Clark AJ, Schildknegt K, Obach RS, Ripp SL, Spracklin DK, Tremaine LM, and Vaz AD (2012) Deuterium isotope effects on drug pharmacokinetics. I. System-dependent effects of specific deuteration with aldehyde oxidase cleared drugs. Drug Metab Dispos 40:625-634.

Sodhi JK, Wong S, Kirkpatrick DS, Liu L, Khojasteh SC, Hop CE, Barr JT, Jones JP, and Halladay JS (2015) A novel reaction mediated by human aldehyde oxidase: amide hydrolysis of GDC-0834. Drug Metab Dispos 43:908-915.

Strelevitz TJ, Orozco CC, and Obach RS (2012) Hydralazine as a selective probe inactivator of aldehyde oxidase in human hepatocytes: estimation of the contribution of aldehyde oxidase to metabolic clearance. Drug Metab Dispos 40:1441-1448.

Tan WK, Tan ARY, Sivanandam P, Goh EJH, Yap ZP, Saburulla NF, Austin-Muttitt K, Mullins JGL, and Lau AJ (2020) In vitro inhibition of human aldehyde oxidase activity by clinically relevant concentrations of gefitinib and erlotinib: comparison with select metabolites, molecular docking analysis, and impact on hepatic metabolism of zaleplon and methotrexate. J Pharmacol Exp Ther 374:295-307.

Terao M, Romão MJ, Leimkühler S, Bolis M, Fratelli M, Coelho C, Santos-Silva T, and Garattini E (2016) Structure and function of mammalian aldehyde oxidases. Arch Toxicol 90:753-780.

Uehara S, Yoneda N, Higuchi Y, Yamazaki H, and Suemizu H (2020) Human aldehyde oxidase 1-mediated carbazeran oxidation in chimeric TK-NOG mice transplanted with human hepatocytes. Drug Metab Dispos 48:580-586.

Xie J, Saburulla NF, Chen S, Wong SY, Yap ZP, Zhang LH, and Lau AJ (2019) Evaluation of carbazeran 4-oxidation and $O^{6}$-benzylguanine 8-oxidation as catalytic markers of human aldehyde oxidase: impact of cytosolic contamination of liver microsomes. Drug Metab Dispos 47:26-37.

Zientek M, Jiang Y, Youdim K, and Obach RS (2010) In vitro-in vivo correlation for intrinsic clearance for drugs metabolized by human aldehyde oxidase. Drug Metab Dispos 38:1322-1327.

Address correspondence to: Kirk D. Kozminski, Takeda Pharmaceuticals Limited, 9625 Towne Centre Drive, San Diego, CA 92121. E-mail: kirk.kozminski@ takeda.com 